\title{
Erratum to: The Design Trends of Keystream Generator for Stream Cipher for High Immunity Attacks
}

\author{
Saif Uldun Mostfa Kamal, Hayder Saad, Mustafa Musa Jaber, \\ Mohammed Hasan Ali and Karam Dhafer
}

\section{Erratum to:}

Chapter 74 in: H.A. Sulaiman et al. (eds.), Advanced Computer and Communication Engineering Technology, Lecture Notes in Electrical Engineering 362, DOI 10.1007/978-3-319-24584-3_74

The subjected book was inadvertently published with an incorrect author's name as Saifuldun Mostafa. The correct author name is "Saif Uldun Mostfa Kamal". The erratum chapter is updated with the correct name.

The updated original online version for this chapter can be found at 10.1007/978-3-319-24584-3_74

S.U. Mostfa Kamal $(\bowtie) \cdot$ H. Saad · K. Dhafer

Faculty of Computer Science, UKM, Selangor, Malaysia

e-mail: saifaldeenalsamir@gmail.com

H. Saad

e-mail: haydersaad@gmail.com

K. Dhafer

e-mail: karamdhafer@gmail.com

M.M. Jaber

Biomedical Computing and Engineering Technologies (BIOCORE) Applied Research Group, Universiti Teknikal Malaysia Melaka (UTeM), Melaka, Malaysia e-mail: mustafamusajaber@yahoo.com

M.H. Ali

Faculty of Computer Science and Software Engineering, Universiti Malaysia Pahang,

Pahang, Malaysia

e-mail: eng.mohammed12@yahoo.com 